\title{
Determining and Ranking of CSFs for Design Capabilities Development in Malaysian
} Automotive Vendors.

\begin{abstract}
Competition dynamically pushes manufacturing ahead. Consequently, design capabilities identified as strategic weapon that offers tremendous opportunities. However, design capabilities development is a stringent challenge to an organization especially in high technology base like automotive. In Malaysia, especially vendors has limited capabilities consequently bound the development steps. There are numerous critical success factors (CSFs) involved in developing successful design capabilities. Thus, makes the development process more complicated. All important CSFs have to be determined and rank accordingly. The CSFs are then applied in a model, using multi criteria decision making approach to facilitate the development process.
\end{abstract}

Keyword: Component; Design capabilities; Malaysian automotive industry; Critical success factors; Multi criteria decision making 